\title{
THE FACE OF WHAT CAME AFTER: MEMORIALIZATION OF SEPTEMBER 11 IN NEWS IMAGES AND THE SHANKSVILLE SITE
}

\author{
G. Robert Britten
}

\section{Dr. C. Zoe Smith, Dissertation Supervisor}

\begin{abstract}
This dissertation examines the memorialization of the September 11 attacks in newspaper photography and in Shanksville, Pennsylvania, the site of the Flight 93 crash. It is based on the premise that the face of memorialization seen in the news media is very different than the practices seen at the Shanksville site itself. Unlike the other impact sites, the Shanksville area was not widely known prior to the attacks, and even since then, it has seemed to be a rare presence on the news page. Yet memorialization has taken place throughout the area, and while the official memorial has repeatedly stalled, residents have moved ahead with individual visions of the event.

To understand the role of this unseen site in the memorialization process, this study is guided by the cultural concepts of place, collective memory, and framing. The first two of these are used to explain how individuals make meaning of where they live and what they do; the third concept deals with how they share those meanings with others. Analysis takes place at two levels: Media and regional. At the media level, content analysis is conducted on images in the major newspapers serving each of the impact sites. At the regional level, the case study method is used to examine the memorial work on the ground in the Shanksville area. The results suggest a journalism of "we" at play, with media tending to focus only on the memorialization activities of their own areas. The implication is that place limits, both individual and institutional, may keep audiences from understanding the parallel memorial work of others.
\end{abstract}

